\title{
Fatigue Life Prediction of a Rocket Combustion Chamber
}

\author{
Aneena Babu ${ }^{1}$, A.K.Asraff ${ }^{2}$, Nivin Philip ${ }^{3}$ \\ ${ }^{I}$ Graduate Student, Department of Civil Engg, Mar Athanasius College of Engg, Kothamangalam, Ernakulam \\ ${ }^{2}$ Group Head, Structural Dynamics \& Analysis Group, Liquid Propulsion Systems Centre, Valiamala \\ ${ }^{3}$ Assistant Professor, Department of Civil Engg, Mar Athanasius College of Engg, Kothamangalam, Ernakulam
}

\begin{abstract}
Cryogenic engines are commonly used in rockets for launching geosynchronous class satellites. The thrust chamber of cryogenic engines is generally of double walled construction. A high conductivity copper alloy is usually selected for the inner wall in regions of high heat flux and for other regions stainless steel is chosen. The failure of a thrust chamber is due to low cycle fatigue, creep of the inner wall, and thermal ratcheting. Present work deals with the study of different plasticity models for the cyclic stress analysis of a double walled cryogenic rocket engine thrust chamber. The work is done using ANSYS (Version 15) finite element code. Different plasticity models used for a simple cubic block showed that a combination of Chaboche's non linear kinematic hardening model in association with multilinear isotropic hardening and creep models is the best suited for cyclic stress analysis of the chamber. Cu-Cr-Zr-Ti alloy is investigated here as it is used in the inner wall of the thrust chamber. Material properties are taken from literature. A comparison of two dimensional (plane strain) and three dimensional cross section of thrust chamber is done. Cyclic life of the chamber is calculated from the cyclic stress-strain graph obtained from above analyses.
\end{abstract}

Keywords: Creep, cyclic stress-strain, high temperature, low cycle fatigue, Chaboche model, ratchetting.

\section{Introduction}

Liquid Propellant Rocket Engines (LPRE) are commonly used in space technology. Thrust chamber is one of the most important subsystems of a rocket engine. Here the liquid propellants are metered, injected, atomized, vaporized, mixed and burned to form hot reaction gas products, which in turn are accelerated and ejected at supersonic velocity. A rocket thrust chamber assembly has an injector, a combustion chamber, a supersonic nozzle, propellant inlet and distribution manifolds, mounting provisions and ignition device. The thrust chamber of a rocket engine generates propulsive thrust force for flight of the rocket by ejection of combustion products at supersonic speeds.

The modes of failure of a thrust chamber are (1) low cycle fatigue caused by the plastic deformation of inner wall during multiple operations, (2) high temperature rate dependent inelastic strain called creep of the inner wall, (3) cyclic accumulation of plastic strain in the inner wall known as thermal ratcheting [1]. The principal mode of failure of a double walled thrust chamber is by bending, bulging up (known as dog house effect) and finally rupture of inner wall ligament.

Cyclic stress analysis of two dimensional finite element model of thrust chamber (either plane strain, plane stress or axisymmetric) is described in [2- 5]. No effort was made so far to model the three dimensional nature of the chamber. Most of the literature published by European and American space agencies dealt with copper alloy such as NARloy-Z [6]. Though there are plenty of metal plasticity models available in various standard nonlinear finite element analysis packages, a comprehensive study and review of them and their suitability for cyclic loading and creep analysis of thrust chamber has not been found.

Finite element analysis of the thrust chamber using two dimensional and three dimensional models have been conducted using ANSYS general purpose analysis software to study the suitability of various metal plasticity models available in the code. Mechanical, fatigue and creep properties of the copper alloy have been adopted from the results published by earlier investigators in this field. Fatigue life of the chamber is computed by employing the Coffin-Mansion rule.

\subsection{Low Cycle Fatigue}

Metals subjected to a repetitive or fluctuating stress will fail at a stress lower than that required to cause fracture on a single application of load. Failures occurring under conditions of dynamic loading are called fatigue failures. Fatigue failures occurring at relatively high stress and low number of cycles (of the order $<10^{4}$ ) are termed as low cycle fatigue failures. Low Cycle Fatigue (LCF) is an important consideration in the design and operation of high temperature systems that are subjected to repeated thermal stresses as a result of temperature gradients which occur on heating and cooling during start-up and shut-downs or during the thermal transients.

Metals fatigue because of local concentrations of plastic strain. A metal, originally in some state of hardness, generally will either harden further or soften when subjected to uniform cyclic loading. For some 
materials, the hardening/softening "saturates" after a small number of cycles. Other materials continue to harden or soften up to the point of final failure. In the study of fatigue hardening, the strain controlled test has been used [7]. The terms cyclic hardening and cyclic softening are used commonly in describing fatigue. "Fig.1" illustrates cyclic hardening and cyclic softening for strain controlled cycling.
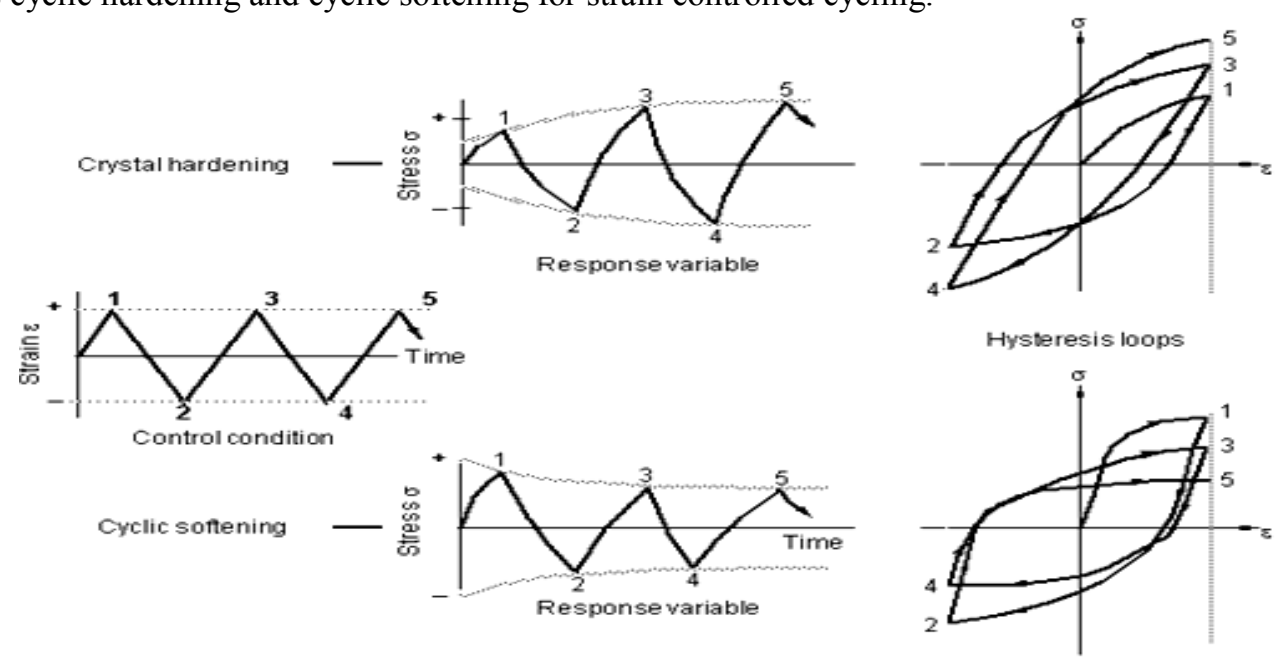

Fig.1. Cyclic hardening and cyclic softening [7]

The usual way of presenting low-cycle fatigue test results is to plot the plastic strain amplitude $\Delta \varepsilon_{\mathrm{p}} / 2$ against N. "Fig.2" shows the straight line obtained when plotted on log-log coordinates. This type of behavior is known as the Coffin-Manson relation [7], which is described by:

$$
\frac{\Delta \varepsilon_{p}}{2}=\bar{\varepsilon}_{f}\left(2 N_{f}\right)^{c}
$$

where $\frac{\Delta \varepsilon_{p}}{2}=$ plastic strain amplitude

$\bar{\varepsilon}_{f}=$ fatigue ductility coefficient defined by the strain intercept at $2 \mathrm{~N}_{\mathrm{f}}=1$

$2 \mathrm{~N}_{\mathrm{f}}=$ number of strain reversals to failure

$\mathrm{c}=$ fatigue ductility exponent, which varies from -0.5 and -0.7

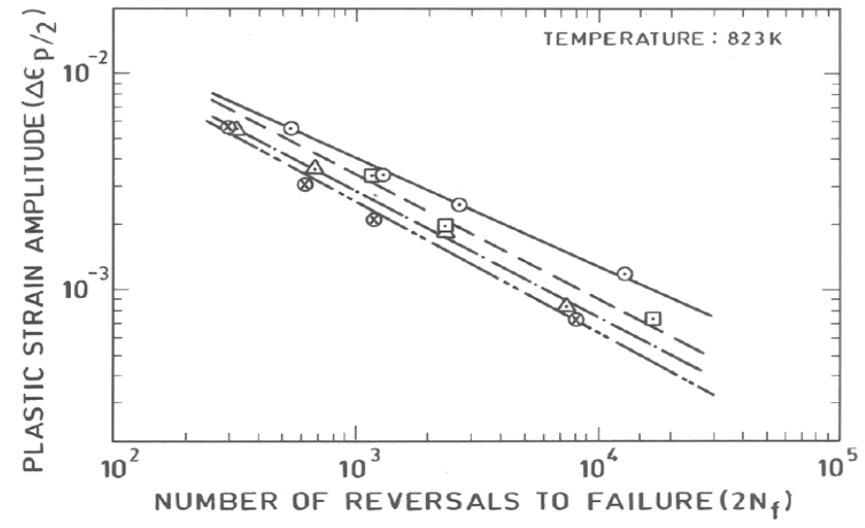

Fig.2. Typical LCF Test Result Curve [7]

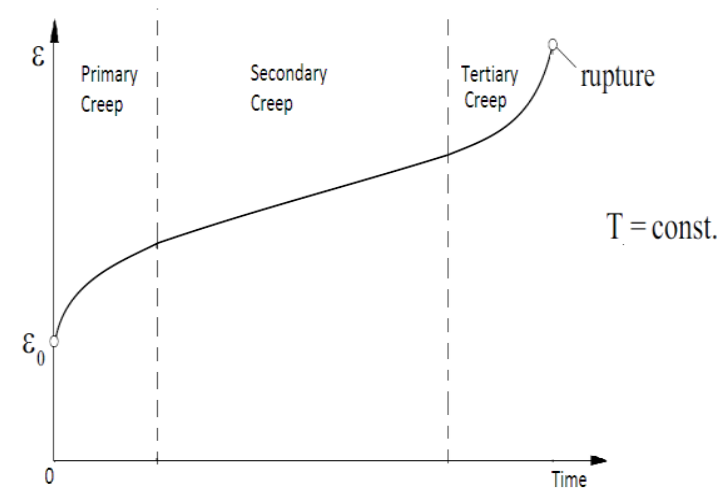

Fig.3. Typical Creep Curve [12]

\subsection{Creep}

Creep can be defined as flow or variation of strain of materials, at constant stress with respect to time. Creep occurs at absolute temperatures greater than 0.4 times the absolute melting. This relative temperature $\frac{T}{T_{m}}$ is known as homologous temperature. Creep occurs at $\mathrm{T}>0.4 \mathrm{~T}_{\mathrm{m}}$. To determine the engineering creep curve of a metal, a constant load is applied to a tensile specimen maintained at a constant temperature, and the strain of specimen is determined as a function of time. The general procedures of creep testing are covered in ASTM EI 39-70 specification [8]. 
"Fig.3" illustrates the idealized shape of creep curve. The slope of this curve $\left(\frac{d \varepsilon}{d t}\right.$ or $\left.\dot{\varepsilon}\right)$ is referred to as the creep strain rate. The first stage of creep, known as primary creep, represents a region of decreasing creep strain rate. The second stage of creep, known also as secondary creep, is a period of nearly constant creep strain rate. It is also called steady-state creep. Third-stage or tertiary creep mainly occurs in constant load creep tests at high stresses at high temperatures. In the materials under consideration, it was found that primary and tertiary creep are negligible and secondary creep is important.

Out of the various creep models available in ANSYS (Version 15), Norton secondary creep model is chosen in the study. The creep equation is given by $[2,4,9]$ :

$$
\begin{aligned}
& \dot{\varepsilon}_{c r}=C_{1} \sigma^{c_{2}} e^{\frac{-c_{3}}{T}} \\
& \text { where } \dot{\varepsilon}_{c r} \quad=\text { creep strain rate } \\
& \sigma \quad=\text { stress } \\
& \mathrm{T}=\text { temperature }
\end{aligned}
$$

\subsection{Plasticity Models}

Plasticity models provide a mathematical relationship that characterizes the elasto-plastic response of materials. The choice of plasticity model depends on the experimental data available to fit the material constants. The basic requirements of a plasticity model include yield criterion, flow rule and hardening rule [9]. Conventional plasticity models are classified as:

- Linear isotropic hardening models

- Linear kinematic hardening models

- Nonlinear isotropic hardening models

- Nonlinear kinematic hardening models

\subsubsection{Linear isotropic hardening models}

These models are appropriate for large strain, proportional loading situations. They are less preferred for cyclic loading since isotropic hardening model alone is incapable of describing cyclic behaviour that shows repeated cyclic deformation. However these models are capable of simulating complex cyclic behaviour when combined with kinematic hardening models [10].

\subsubsection{Linear kinematic hardening models}

They follow a linear hardening curve in cyclic loading situations. The hardening rule is given by [11]:

$$
d \alpha_{i j}=c d \varepsilon_{i j}^{p}
$$

where

$$
\begin{array}{ll}
d \alpha_{i j} & =\text { incremental back stress } \\
d \varepsilon_{i j}^{p} & =\text { incremental plastic strain } \\
c & =\text { material parameter }
\end{array}
$$

They can describe stable loops in cyclic loading, including the Bauschinger effect. However, for a prescribed uniaxial stress cycle with a mean nonzero stress, they fail to distinguish between shapes of the loading and reverse loading hysteresis curves and consequently produce a closed loop with no ratchetting [10].

\subsubsection{Non-linear kinematic hardening models}

They follow a smooth non linear hardening curve in cyclic loading situations. The hardening rule is given by [11]

$$
d \alpha_{i j}=\frac{2}{3} c d \varepsilon_{i j}^{p}-\gamma \alpha d p
$$

where

$$
\begin{array}{ll}
\alpha & =\text { back stress } \\
d p & =\text { accumulated plastic strain } \\
\gamma & =\text { material parameter }
\end{array}
$$


They can simulate ratchetting and shakedown effects in an FEA simulation.

\subsection{Chaboche Model}

The Chaboche model is a type of non linear kinematic hardening model commonly used to simulate the plastic deformation of metals. Chaboche model is based on the well known von Mises yield criterion. The yield function is given by $[12,13]$ :

(5)

$$
F=\sqrt{\frac{3[\{S\}-\{\alpha\}]^{T}[M][\{S\}-\{\alpha\}]}{2}}-R=0
$$

where

$\{S\}=$ deviatoric stress tensor

$\{\alpha\}=$ back stress tensor

$[M]=$ matrix containing information on different yield strengths in different directions

$R=$ initial yield stress

\section{Cyclic Stress Analysis Of A Simple Block}

Stress analysis of a simple block is carried out as explained in [10] to simulate the cyclic behaviour occurring under symmetric pressure as well as displacement loading conditions. The material models investigated include:

1. BISO (Bilinear isotropic hardening) model + CREEP model

2. BKIN(Bilinear kinematic hardening) model + CREEP model

3. MISO (Multilinear isotropic hardening) model + CREEP model

4. $\mathrm{MISO}+$ Chaboche + CREEP model

To capture the cyclic behavior, a single SOLID185 element is used with quarter symmetry boundary conditions and uniaxial displacement in the $\mathrm{Y}$ direction. Elastic properties for the special copper alloy $\mathrm{C} \mathrm{Cu}-\mathrm{Cr}-$ $\mathrm{Zr}$-Ti) are Young's modulus of $110660 \mathrm{MPa}$ and Poisson's ratio of 0.3. "Fig.4" shows the FE model of a simple block. The Chaboche model parameters used in the present study are taken from [10] and depicted in "TABLE $1 "$. Creep parameters taken from [4] are depicted in "TABLE 2".

Table 1 Chaboche parameters at $900 \mathrm{~K}[9]$

\begin{tabular}{|c|c|c|c|}
\hline Sl. No & Parameters & Initial values & Fitted values \\
\hline 1 & $\mathrm{C}_{1}$ & 330000 & 329433.77 \\
\hline 2 & $\gamma_{1}$ & 200000 & 200987.64 \\
\hline 3 & $\mathrm{C}_{2}$ & 16000 & 40220.46 \\
\hline 4 & $\gamma_{2}$ & 1000 & 1107.84 \\
\hline 5 & $\mathrm{C}_{3}$ & 577 & 163.77 \\
\hline 6 & $\gamma_{3}$ & 9 & 9 \\
\hline 7 & $\sigma_{0}$ & 32 & 32 \\
\hline
\end{tabular}

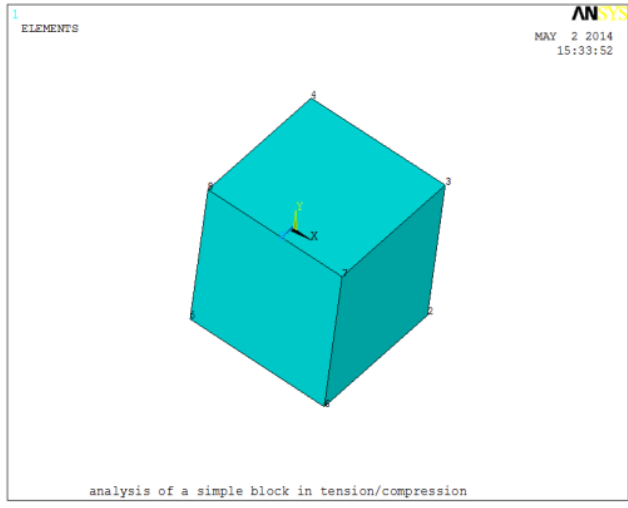

Fig.4. FE model of simple block

Table 2 Norton creep constants [4]

\begin{tabular}{|c|c|}
\hline $\mathrm{C}_{1}$ & $8.091 \mathrm{e}-06$ \\
\hline $\mathrm{C}_{2}$ & 2.72102 \\
\hline $\mathrm{C}_{3}$ & 12843.12959 \\
\hline
\end{tabular}

\subsection{Stress Analysis Results}

\subsubsection{Displacement loading}

"Fig.5" shows axial stress-strain variation for BISO + Creep model. The variation of axial stress-strain for BKIN + Creep model is plotted in "Fig.6". "Fig.7" and "Fig.8" highlight the variation of axial stress-strain for MISO + Creep model and MISO + Chaboche + Creep model respectively. In case of displacement loading for all the above combinations considered it is seen that the stress relaxation or creep is very large. 


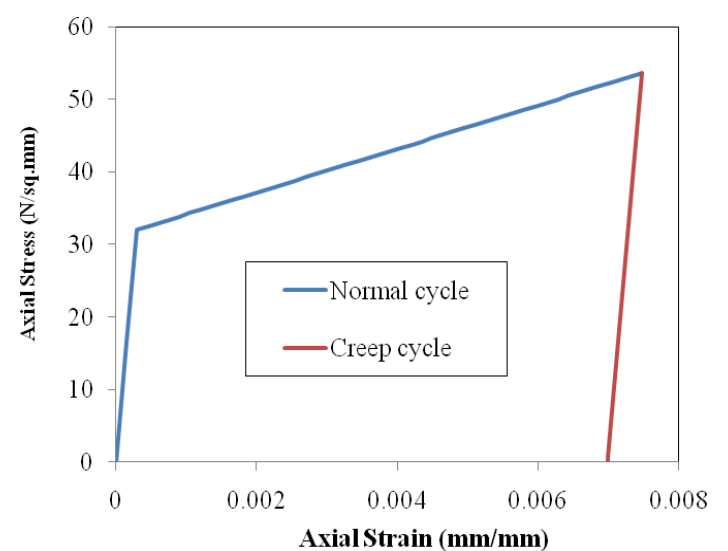

Fig.5. Axial stress-strain graph for $\mathrm{BISO}+$ Creep model

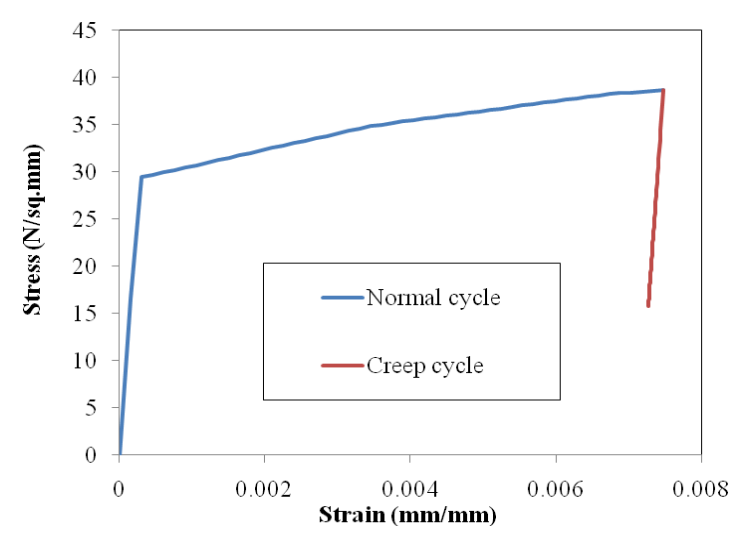

Fig.7. Axial stress-strain graph for $\mathrm{MISO}+$ Creep model

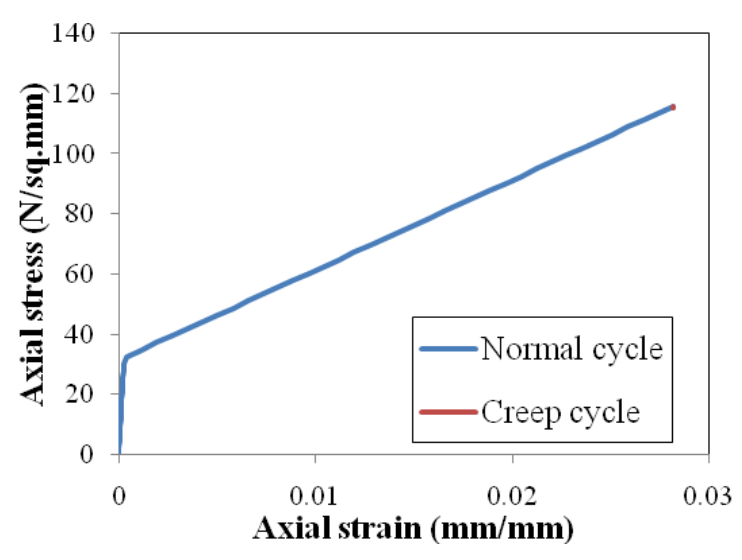

Fig.9. Axial stress-strain graph for $\mathrm{BISO}+$ Creep model

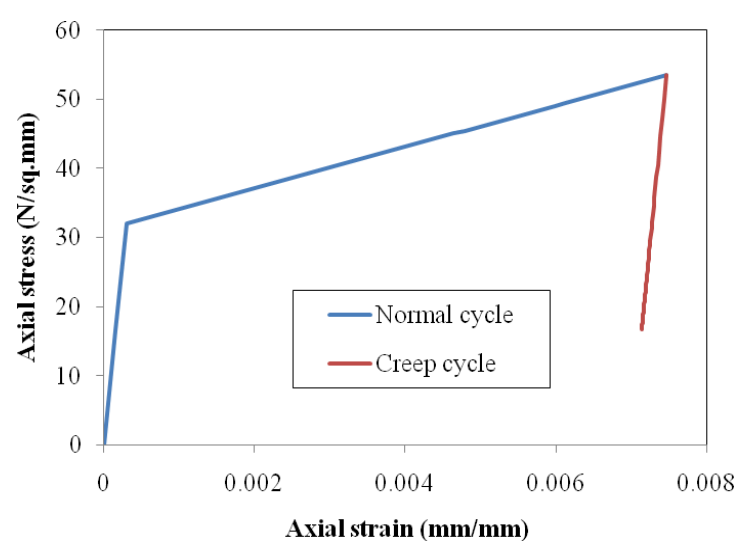

Fig.6. Axial stress-strain graph for BKIN + Creep model

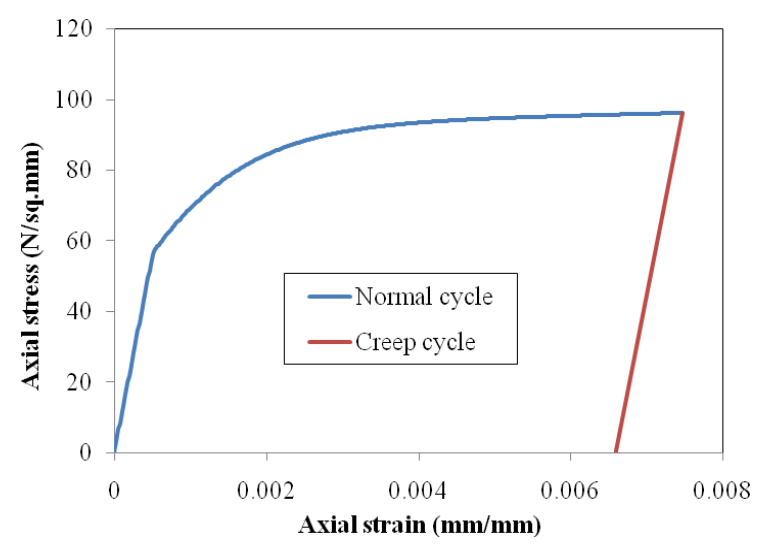

Fig.8. Axial stress-strain graph for MISO + Chaboche + Creep model

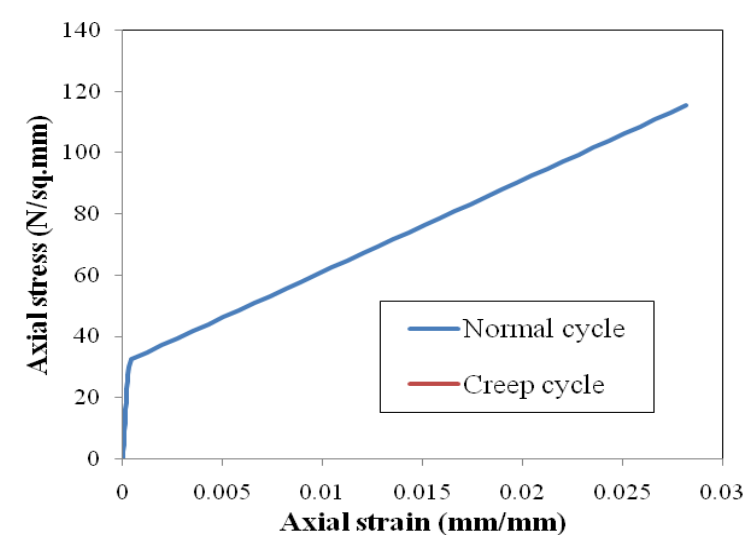

Fig.10. Axial stress-strain graph for BKIN + Creep model

\subsubsection{Pressure loading}

"Fig.9" shows axial stress-strain variation for Creep + BISO model. The variation of axial stress-strain for Creep + BKIN model is plotted in "Fig.10". "Fig.11" and "Fig.12" highlight the variation of axial stressstrain for Creep + MISO model and Creep + MISO + Chaboche model respectively. For pressure loading, it was found that the creep strain is very less. 


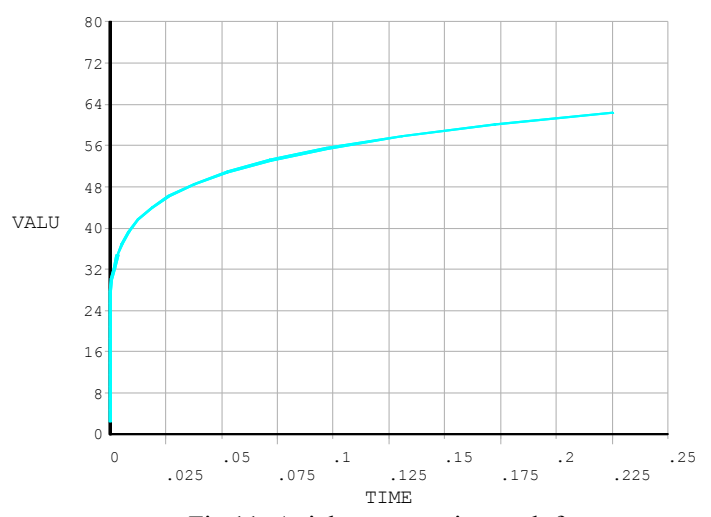

Fig.11. Axial stress-strain graph for MISO + Creep model

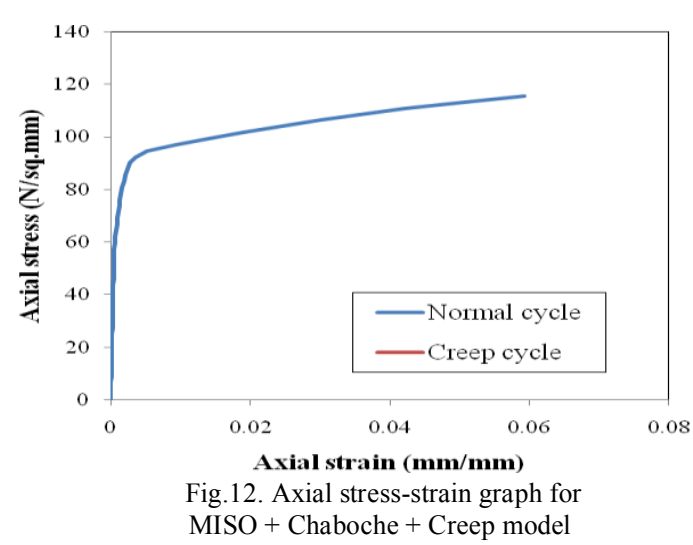

\section{Two Dimensional Cyclic Stress Analysis Of Thrust Chamber}

Combustion of the fuel and oxidizer inside the thrust chamber induces high thermal and pressure loads on inner wall and also the passage of coolant through coolant channels imparts shrinkage and pressure loads. Thermal and pressure loads were applied in 7 different load steps simulating the complete sequence of hot testing of the chamber viz. (i) pre-chilling (ii) start up transient (iii) steady state combustion (iv) creep for a duration of 6500 seconds (v) shut down transient (vi) post chilling and (vii) unloading to ambient [3]. The duration of operation of the thrust chamber at peak load is $650 \mathrm{~s}$ and a factor of safety of 10 has been used to arrive at the creep analysis duration of $6500 \mathrm{~s}$. Cross-section considered is at a distance of $350 \mathrm{~mm}$ from injector end (near throat). "Fig.13" and "Fig.14" show the details of cross section chosen and 2D FE model of crosssection. PLANE182 element is used in structural analysis and PLANE55 element is used in thermal analysis.

Cyclic stress analysis of the thrust chamber is done as a 2D Finite element plane strain model of its cross section using:

\section{- $\quad$ BISO model + Creep model}

- $\quad$ BKIN model + Creep model

- $\quad$ MISO model + Creep model

for inner wall copper and BKIN model for outer wall steel. Analysis is carried out considering temperature loads alone as well as temperature and pressure loads separately. Analysis is done for two successive hot tests.

The chamber pressure, coolant pressure and temperature at the inner and outer surfaces of the inner and outer walls at the throat are given in "TABLE 3". "Fig.15" compares the hoop stress-strain graphs of different material model combinations. Ratchetting is observed in hot gas inner wall at mid channel section in all cases. When MISO + CREEP is used, the hoop stress- hoop strain curve is good with significant ratchetting. Use of BISO + CREEP model resulted in a smooth curve with very less ratchetting. BKIN + CREEP model showed a comparatively flatter hoop stress-hoop strain curve. So MISO + CREEP can be considered as the best model for creep modelling.

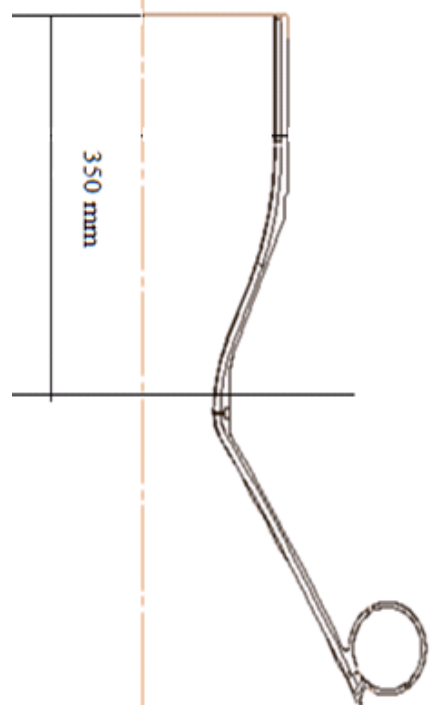

Fig.13. Details of cross section chosen

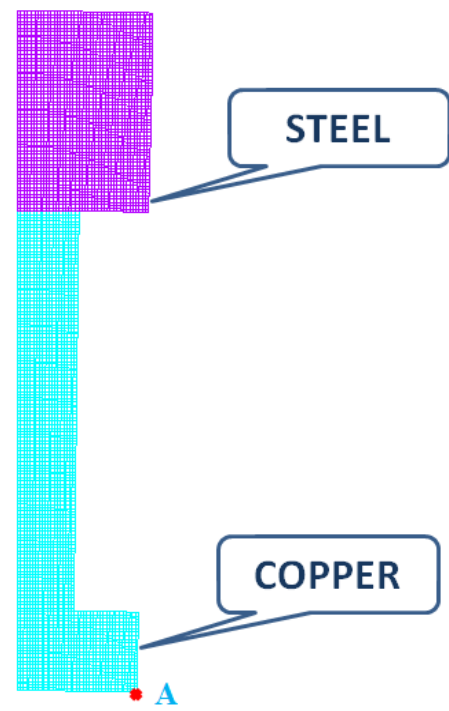

Fig.14. FE model of cross section near throat 
Table 3 Pressure and thermal loads at the throat of chamber

\begin{tabular}{|c|c|c|c|c|}
\hline $\begin{array}{c}\text { Gas Pressure, } \mathrm{p}_{\mathrm{g}} \\
\left(\mathrm{N} / \mathrm{mm}^{2}\right)\end{array}$ & $\begin{array}{c}\text { Coolant Pressure, } \\
\mathrm{p}_{\mathrm{co}} \\
\left(\mathrm{N} / \mathrm{mm}^{2}\right)\end{array}$ & $\begin{array}{c}\text { Gas side wall } \\
\text { temperature } \mathrm{T}_{\mathrm{wg}}(\mathrm{K})\end{array}$ & $\begin{array}{c}\text { Coolant side inner } \\
\text { shell temperature } \\
\mathrm{T}_{\mathrm{wc}}(\mathrm{K})\end{array}$ & $\begin{array}{c}\text { Coolant side outer shell } \\
\text { temperature } \mathrm{T}_{\mathrm{c}}(\mathrm{K})\end{array}$ \\
\hline 3.26 & 9.08 & 769 & 573.6 & $\begin{array}{c}\text { Outer wall } \\
\text { outer } \\
\text { temperature } \mathrm{T}_{\mathrm{co}} \\
(\mathrm{K})\end{array}$ \\
\hline
\end{tabular}

\section{Three Dimensional Cyclic Stress Analysis Of Thrust Chamber}

Three dimensional cyclic stress analysis of thrust chamber cross-section is carried out in ANSYS (Version 15) finite element code. SOLID185 element is used for modelling the section. The section considered is at a distance of $350 \mathrm{~mm}$ from injector end (near throat). "Fig.16" shows the FE model of the section considered. Different model combinations used for inner wall copper are:

- $\quad$ BISO + Creep model

- $\quad$ BKIN + Creep model

- $\quad$ MISO + Creep model

BKIN was chosen for the outer wall stainless steel. Cross-section is extruded by $0.1 \mathrm{~mm}$ length in Zdirection. All $\mathrm{Z}=0$ nodes are arrested in $\mathrm{Z}$-direction. At $\mathrm{Z}=0.1 \mathrm{~mm}$, all the nodes are coupled along $\mathrm{Z}$ direction. Analysis is done for two successive hot tests.

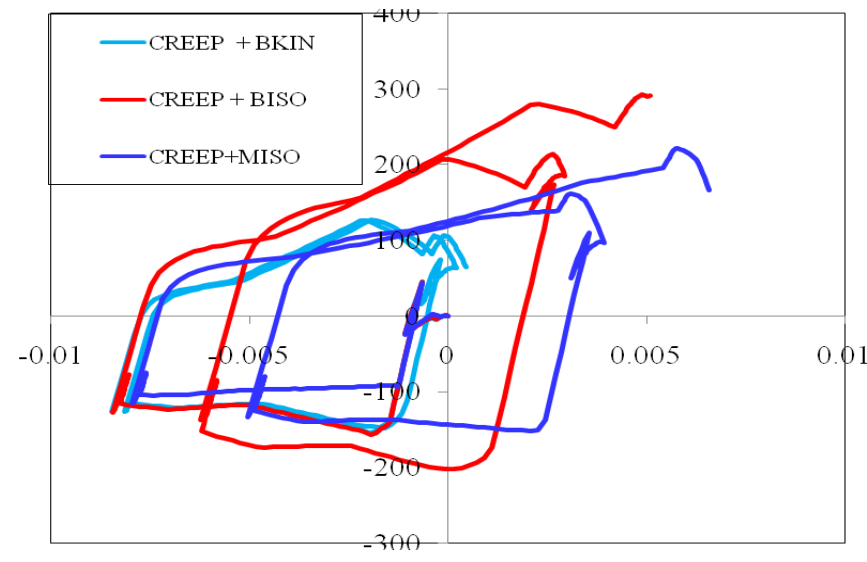

Fig.15. Variation of hoop stress-hoop strain at location "A" (MISO + Creep model)

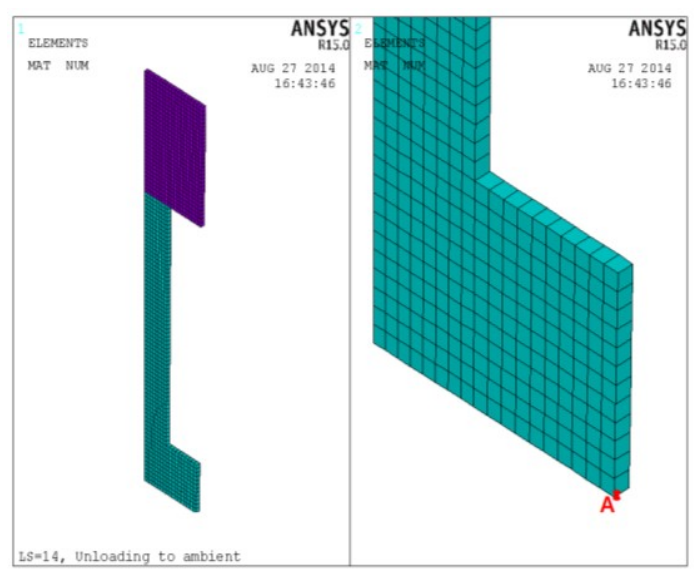

Fig.16. Finite element model of cross-section

"Fig. 17" compares the hoop stress-strain graphs for MISO + Creep model from 2D and 3D modelling. The graph starts moving in the negative direction when modelled as 2D plane strain model. This is due to the Poisson's effect which arises due to the boundary conditions imposed. The hoop stress-strain graph obtained from 3D analysis is better than the one obtained from 2D plane strain model. It is found that equilibrium of forces in $\mathrm{Z}$ direction is ensured in 3D. But this is not applicable for 2D. Plane strain model has net stresses in $\mathrm{Z}$ direction, which result in a net strain in $\mathrm{Z}$ direction. This causes Poisson's strain is $\mathrm{X}$ and $\mathrm{Y}$ direction which contribute to a net stress in $\mathrm{X}$ and $\mathrm{Y}$ direction for $2 \mathrm{D}$ model. From the graphs it is seen that the effect of creep is negligible.

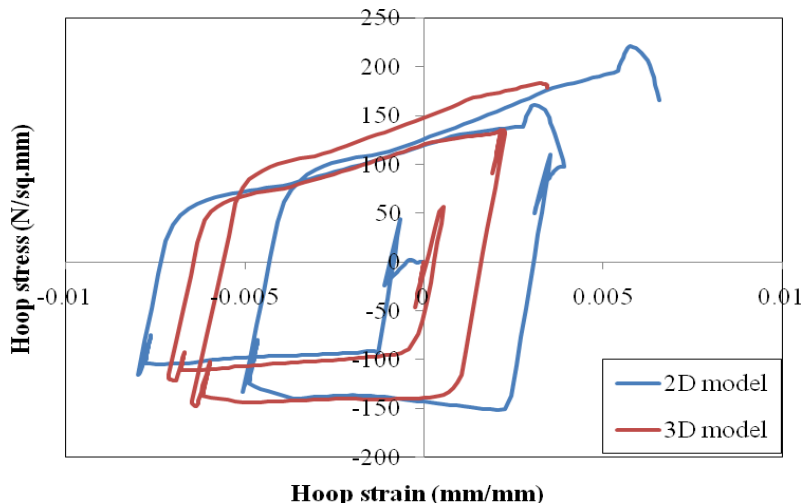

Fig.17. Comparison of hoop stress-strain graphs

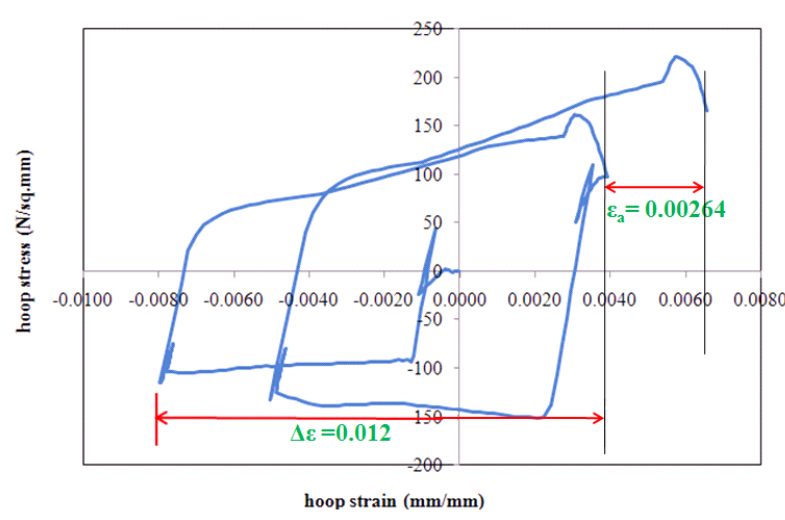

Fig.18. Curve for finding $\Delta \varepsilon$ for $2 \mathrm{D}$ and $3 \mathrm{D}$ modelling 


\section{Fatigue Life Prediction}

The Coffin Manson equation as explained before is given by (1). Based on the LCF test conducted for the copper alloy, the actual Coffin Mansion equation for the copper alloy is [2]:

$$
N_{L C F}=\frac{0.2872}{(\Delta \varepsilon)^{1.596}}
$$

where $\Delta \varepsilon$ is in fractional form. The value of $\Delta \varepsilon$ is obtained as explained in "Fig.18" for two dimensional plane strain cross section using the Creep + MISO model.

Substituting the value of $\Delta \varepsilon$ in (6), we get

$$
N_{L C F}=334.05 \text { cycles }
$$

The cyclic damage factor $f_{L C F}$ is calculated as $[2,3]$

$$
f_{L C F}=\frac{1}{N_{L C F}}
$$

Number of cycles to failure considering ratchetting is given by $[2,3]$ :

$$
N_{\text {ratchetting }}=\left(\frac{\varepsilon_{f}}{\varepsilon_{r}}\right)
$$

where $\varepsilon_{f}$ is the fracture strain of the material and $\varepsilon_{r}$ is ratchetting strain at the end of the cycle.

$$
\begin{aligned}
& \varepsilon_{f}=\ln \left(\frac{1}{1-R A}\right) \\
& \varepsilon_{f}=\ln \left(\frac{1}{1-0.85}\right)=1.897 \\
& N_{\text {ratchettitg }}=\left(\frac{1.897}{0.00264}\right)=718.179
\end{aligned}
$$

Thermal ratchetting damage factor $f_{\text {ratchettivg }}$ is calculated as $[2,3]$

$$
f_{\text {ratchettig }}=\frac{1}{N_{\text {ratchetting }}}
$$

The total damage factor $f_{t}$ due to LCF and ratchetting is the sum of all [2].

$$
\begin{aligned}
& f_{t}=f_{L C F}+f_{\text {ratchetting }} \\
& f_{t}=\frac{1}{334.05}+\frac{1}{718.179}=4.385 \times 10^{-3}
\end{aligned}
$$

Number of cycles to failure:

$$
N_{f}=\frac{1}{f_{t}}=227.99
$$

Table 4 Results of cyclic life prediction

\begin{tabular}{|c|c|c|c|c|c|}
\hline Type & $\boldsymbol{\Delta} \boldsymbol{\varepsilon}(\mathbf{m m} / \mathbf{m m})$ & $\mathbf{N}_{\mathbf{L C F}}$ & $\mathbf{N}_{\text {ratchetting }}$ & $\mathbf{N}_{\mathbf{f}}$ & $\mathbf{N}_{\mathbf{a}}$ (allowable number of cycles) \\
\hline $\begin{array}{c}\text { MISO + Creep model } \\
\text { in 2D }\end{array}$ & 0.012 & 334.05 & 718.179 & 227.99 & 57 \\
\hline $\begin{array}{c}\text { MISO + Creep model } \\
\text { in 3D }\end{array}$ & 0.0071 & 501.75 & 718.179 & 295.38 & 73 \\
\hline
\end{tabular}




\section{Conclusion}

The main objectives of the present study were to explore different metal plasticity models for cyclic stress analysis of a double walled rocket engine thrust chamber. A study of different elasto plastic material models available in ANSYS (Version 15) code was made and the following models were found to be suitable for the present investigation: BISO, BKIN, MISO, CHABOCHE and CREEP. A special copper alloy (Cu-Cr$\mathrm{Zr}$-Ti alloy) is chosen for the study. This alloy is used for the fabrication of the inner wall of a double walled thrust chamber of an indigenously designed cryogenic rocket engine. Following model combinations were tried : BISO+CREEP, BKIN+CREEP, MISO+CREEP, MISO+CHABOCHE on cyclic stress analysis of a simple cubical block under axial loading at a uniform temperature of $900 \mathrm{~K}$. Both displacement and pressure controlled loadings were explored. Creep phenomenon was found to be negligible for pressure loading while it was found significant for displacement loading.

Finite element modelling of the thrust chamber was done using two dimensional plane strain model of a cross section taken near the throat. Subsequently, the above models/model combinations (except CHABOCHE) were applied for the above 2D model. Chaboche parameters were available only at a temperature of $900 \mathrm{~K}$ and hence this model could not be used for the analysis of the thrust chamber since it experiences temperature gradients. Three dimensional FE modelling of the above cross section was also conducted and the results compared with that from 2D. It was found that the 3D model gave better results compared to 2D since the assumption of plane strain condition induces fictitious stresses/strains in the axial direction of the chamber due to Poisson's effect. Further, plane strain model is found to be slightly more conservative than 3D model. However, 3D models are preferable since they are theoretically more accurate even at the expense of higher computing requirement.

\section{References}

[1] A.K.Asraff, Jomon T. Joseph, F.P.Joshua, Y.V.K.Sadasiva Rao, Elasto-Plastic Stress Analysis \& Life Prediction of an Indigenously Designed Cryogenic Rocket Thrust Chamber, Proceedings of 6th International Symposium on Propulsion for Space Transportation of the XXIst Century, Association Aeronautique et Astronautique de France, May 2002, France.

[2] Sunil S, A.K.Asraff, M.R.Sarathchandra Das, Creep Based Stress Analysis of a Cryogenic Rocket Thrust Chamber, Proceedings of 6th National Conference on Technological Trends, College of Engineering, Trivandrum, November, 2005.

[3] Asraff, A.K., Sunil, S., Muthukumar, R., Ramanathan. T.J, New Concepts in Structural Analysis and Design of Double Walled LPRE Thrust Chambers, Proceedings of 42nd AIAA/ASME/SAE/ASEE Joint Propulsion Conference, Sacremento, USA, 2006.

[4] R.Aparna, A.K.Asraff, D.Kumaresan, R.Muthukumar, Comparison of Creep Constitutive Models of Four Copper Alloys and Creep based structural analysis of a Rocket Engine Combustion Chamber, Procedia Engineering, 55, 45-50, 2013.

[5] A.K.Asraff, S.Sheela, Sumi Sam, S.Savithri, R.Vinayaravi, High Temperature Material Modelling of a Copper Alloy for Structural Integrity Assessment of a Rocket Engine Thrust Chamber, Proceeding of First International Conference on Structural Integrity, ICONS-2014, IGCAR, Kalpakkam, February 4-7th, 2013.

[6] R.T.Cook, G.A.Coffey, Space Shuttle Orbiter Engine Main Combustion Chamber Cooling And Life, Proceedings of AIAA/SAE 9th Joint Propulsion Conference, November 1973.

[7] George E.Dieter, Mechanical Metallurgy (Third Edition, McGraw Hill Education (India) Private Limited, 1986).

[8] S.M.A.Kazimi, Solid Mechanics (First Revised Edition, Tata McGraw-Hill Publishing Company Limited,1994)

[9] Anonymous, ANSYS Release 15 On-line Documentation, Theory Reference, Ansys Inc, USA, 2014.

[10] A.K.Asraff, Reeba K. Eapen,Soumya Anand, Cyclic Stress Analysis of a Rocket Engine Thrust Chamber using Chaboche Constitutive Model, Proceedings of National Conference on Futuristics Technologies in Mechanical Engineering, August 2014.

[11] Shafiqul Bari, Tasnim Hassan, Anatomy of Coupled Constitutive Models for Ratcheting Simulation, International Journal of Plasticity, pp 381-409 (2000).

[12] Chaboche, J.L., Constitutive Equations for Cyclic Plasticity and Cyclic Viscoplasticity, 247-302 (1989).

[13] Chaboche. J.L, On Some Modifications of Kinematic Hardening to Improve The Description of Ratchetting Effect, International Journal of Plasticity, pp 661-678 (1991) 